\title{
ESTÁGIO SUPERVISIONADO OBRIGATÓRIO DAS LICENCIATURAS COMO CONTEXTO DE PESQUISA DA LINGUÍSTICA APLICADA
}

\section{COMPULSORY TEACHER TRAINING PRACTICE SUBJECT OF DIFFERENT UNDERGRADUATE TEACHING COURSES AS CONTEXT OF APPLIED LINGUISTICS RESEARCH}

\author{
Wagner Rodrigues Silva* \\ Alline Laís Schoen Diniz
}

\section{RESUMO}

Com propósito de comprovar que estágios supervisionados de diferentes licenciaturas brasileiras, como Geografia e História, no que tange ao uso da linguagem, são contextos relevantes para a investigação científica na Linguística Aplicada, apresentamos um estudo de como professores em formação inicial percebem a alienação do trabalho do professor do ensino básico envolvendo a escrita, em relatórios de estágio supervisionado, utilizados como atividade avaliativa final nas referidas disciplinas obrigatórias das licenciaturas. Os relatórios são tomados como dados a partir da abordagem qualitativa de pesquisa, orientada pela concepção de Linguística Aplicada indisciplinar, caracterizada pela mobilização de pressupostos teórico-metodológicos originários de diferentes áreas do conhecimento, conforme objeto construído para investigação crítica. Os resultados mostram que, normalmente, o professor não é visto institucionalmente como um profissional autônomo, mas as disciplinas de estágio supervisionado das licenciaturas podem servir como um importante contexto para desestabilização da alienação do trabalho docente ainda na formação inicial de professores, sendo a escrita acadêmica reflexiva um importante instrumento para o empoderamento docente.

Palavras-chave: alienação do trabalho; escrita reflexiva; letramento do professor.

\section{ABSTRACT}

With the purpose of proving that language uses at compulsory teacher training practices of different Brazilian Teacher Education Courses, like Geography and History, are relevant contexts to the scientific research in Applied Linguistics, we show a study about how pre-service teachers realize the alienation in school teacher's work involving the writing ability from their supervised training reports used as final assessment on the mentioned compul-

\footnotetext{
* UFT, Araguaína (TO), Brasil. wagnerodriguesilva@hotmail.com; UFT, Araguaína (TO), Brasil/CAPES. allineschoen@gmail.com
} 
sory subjects of undergraduate teaching courses. The written reports are the data examined by the perspective of qualitative research as well as guided by the conception of indisciplinary Applied Linguistics that is characterized by the use of theoretical-methodological assumptions from different areas of knowledge depending on the produced object to be critically investigated. The result shows that the school teacher is not usually recognized as an autonomous professional. Otherwise, the teacher training practice subjects at undergraduate teaching courses must be seen as important contexts to destabilize the school teachers' work alienation still into their pre-service teacher training. The academic reflexive writing can be used as an important instrument to the teacher's empowerment.

Keywords: work alienation; academic writing; teacher education.

\section{INTRODUÇÃO}

Os estágios supervisionados obrigatórios das licenciaturas, que são cursos superiores brasileiros de formação inicial de professores, têm sido frequentemente objeto de investigação na Ciência da Educação ${ }^{1}$. São analisadas desde questões epistemológicas e políticas, relativas ao papel das disciplinas nas licenciaturas, até métodos de ensino utilizados no trabalho pedagógico das disciplinas escolares para as quais os graduandos são, mais diretamente, preparados para atuarem no ensino básico ${ }^{2}$.

As investigações científicas a respeito da disciplina vêm ganhando um olhar diferenciado a partir de pesquisas realizadas na Linguística Aplicada (doravante LA), a exemplo dos trabalhos realizados por Brito (2014); Melo e Gonçalves (2014); Oliveira e Ferreira (2014), Kaneoya (2014); Sousa et al (2014) e Valsechi e Kleiman, (2014). Essas são algumas das pesquisas integrantes do número temático "Estágio Supervisionado nas Licenciaturas", da Revista Raído (v. 8, no 15), volume destinado à LA, que reúne 15 (quinze) artigos selecionados a partir de um quantitativo de 47 submissões (cf. GONÇALVES e SILVA, 2014). A organização do periódico em cinco seções também evidencia a diversidade de enfoques investigativos assumidos nas pesquisas em LA envolvendo o complexo contexto das disciplinas de estágio obrigatório das licenciaturas. As seções integrantes da organização do periódico foram: letramento; prática escolar de linguagem; política de formação inicial; tecnologia no ensino; e inclusão. Esse número temático fora produzido como uma das atividades

1 Este trabalho contribui para o projeto de pesquisa "Escrita reflexiva profissional nas licenciaturas: da gramática ao discurso" (CNPq n ${ }^{\circ}$ 407572/2013-9; PROPESQ/UFT nº AG\#007/2014).

2 Um indício da relevância das investigações científicas sobre os estágios supervisionados das licenciaturas para a Ciência da Educação é o Encontro Nacional de Didática e Prática de Ensino - ENDIPE, evento científico bianual que está na sua $17^{a}$ edição. Reúne significativo número de profissionais de diferentes disciplinas do conhecimento, em especial pedagogos, para discutirem questões em torno da didática e da prática de ensino de diferentes disciplinas, em diferentes contextos e níveis de formação. 
do grupo de pesquisa Práticas de Linguagens em Estágios Supervisionados - PLES (UFT/CNPq), no qual também está inserido o estudo aqui apresentado3.

Diferentemente das pesquisas reunidas no referido periódico, este trabalho se torna inovador por focalizar os estágios supervisionados das Licenciaturas em Geografia e História, revelando, assim como fizeram Diniz (2012), Tavares (2011), Tavares e Silva (2014; 2012), Silva (2012b), Silva e Pereira (2013) e Pereira (2014), todos no âmbito do PLES, que o trabalho com linguagens nas distintas licenciaturas brasileiras também é escopo investigativo da LA, não se limitando aos cursos de formação inicial de professores de línguas.

Neste artigo, focalizamos algumas formas de alienação do trabalho do professor do ensino básico, provocadas por usos sociais da escrita em interações nas instituições em que atuam profissionalmente, onde são realizados os estágios supervisionados obrigatórios das licenciaturas. Nesse sentido, investigamos ainda algumas formas de alienação do trabalho docente, provocadas pela submissão do referido professor a documentos legais ou, até mesmo, pelo descredito incorrido por tais escritos no espaço de atuação profissional. A alienação profissional é testemunhada em relatórios escritos, produzidos nas disciplinas de estágio por professores em formação inicial, sempre denominados de alunos-mestre em nossas pesquisas.

O letramento do professor é focalizado a partir da forma como o aluno-mestre lida com situações de alienação do trabalho docente, envolvendo práticas de leitura e escrita no contexto do estágio supervisionado das licenciaturas focalizadas. A título de exemplo, ao considerarmos a leitura enquanto componente curricular que "apresenta maior dificuldade para o sucesso dos alunos" do ensino básico, não só na escola, mas também nos diversos domínios sociais, precisamos aceitar que o ensino da leitura é uma tarefa para envolver os professores responsáveis por diferentes disciplinas escolares (KLEIMAN e MORAES, 2003, p. 149). Todo professor precisa ser um professor de leitura, responsável pelo ensino e valorização dessa prática social. Todo professor precisa ser um agente de letramento, na condição de que seja significativamente letrado, evitando a alienação profissional do grupo a que pertence, ou seja, "a invasão cultural, domestificação, opressão, mecanicismo, etc." (KIELING, 2008, p. 36)

3 O PLES é composto por membros pertencentes a quatro instituições públicas de ensino, considerando a instituição sede (IFTO, UFPA, UFT, UFU). Atualmente, há quatro teses de doutorado, duas dissertações de mestrado acadêmico e três dissertações de mestrado profissional em produção no grupo.

4 De acordo com Kleiman (2006, p. 86), o agente de letramento é capaz de "mobilizar as capacidades dos membros do grupo, ao favorecer a participação de todos segundo suas capacidades". Ele próprio é "um ator social, cria as condições necessárias para a emergência de diversos atores, com diversos papéis, segundo as necessidades e potencialidades do grupo. A assimetria institucional que aprisiona professor e alunos em papéis imutáveis pode ser desfeita". 
Situamos este trabalho na LA por assumirmos a linguagem como objeto de estudo crítico, atravessada por conflitos originários de relações assimétricas instauradas no complexo contexto dos estágios das licenciaturas. Esse fato diferencia este trabalho das pesquisas a respeito dos estágios das licenciaturas, realizadas na Ciência da Educação. Tal diferenciação não nos impossibilita de dialogar diretamente com estudos produzidos na referida disciplina. De forma mais pontual, inserimos este estudo no campo das pesquisas do letramento do professor, responsável pela investigação do envolvimento da escrita em práticas sociais, realizadas por grupos de pessoas, em torno do trabalho docente.

Este artigo está organizado em três principais seções, além desta Introdução, das Considerações finais e das Referências bibliográficas. Em Percurso investigativo construído, sintetizamos os tipos de pesquisa realizados no PLES, na mesma proporção em que também mostramos a relevância do uso da escrita reflexiva profissional para o empoderamento do letramento do aluno-mestre em diferentes licenciaturas. Em Linguística Aplicada e formação do professor, caracterizamos a perspectiva crítica e indisciplinar de LA assumida e algumas contribuições dos estudos nela desenvolvidos para a formação inicial do professor. Finalmente, em Letramento do aluno-mestre, analisamos as representações de alienação do trabalho do professor do ensino básico, nos testemunhos dos alunos-mestre em relatórios de estágio das Licenciaturas em Geografia e História, procurando evidenciar o posicionamento crítico assumido por eles nas situações relatadas.

\section{PERCURSO INVESTIGATIVO CONSTRUÍDO}

Inúmeros são os objetos de pesquisa passíveis de construção na LA a partir do encontro inevitável entre a universidade e as escolas de ensino básico, proporcionado pelos estágios das licenciaturas. Esse encontro fortalece ainda mais "a importância política da produção de conhecimento em LA através da pesquisa sobre formação nos contextos acadêmicos onde ela é desenvolvida", conforme ressaltado por Miller (2013, p. 101).

Com o interesse em elucidar a formação dos alunos-mestre nos estágios obrigatórios, a trajetória das pesquisas do PLES foi iniciada com a investigação da construção de objetos de ensino em aulas ministradas nas escolas onde os estágios são realizados. Foram pesquisados como os saberes acadêmicos, mais precisamente, os conhecimentos teóricos sobre ensino de língua materna e adicional, produzidos na academia, são recontextualizados nas atividades práticas realizadas pelos alunos- 
-mestre em escolas de ensino básico (cf. GUERRA, 2012; MELO, 2012; SILVA, 2008; SILVA, 2012a; SILVA e MELO, 2010; SILVA e RÊGO, 2013; SILVA et al, 2014; TAVARES e SILVA, 2012). Essas atividades correspondem ao planejamento e às aulas ministradas sob a orientação do professor formador, o qual é responsável pelo estágio supervisionado na universidade. $\mathrm{Na}$ escola de ensino básico, a atenção maior sobre os alunos-mestre recai sobre o professor colaborador da instituição, responsável pela disciplina observada ou assumida temporariamente pelos licenciandos.

O encontro entre as instituições de ensino aqui focalizadas ocorre, normalmente, num momento bastante tardio na concepção de inúmeros alunos-mestre ${ }^{5}$. Os professores formadores, responsáveis pelas demais disciplinas integrantes das matrizes curriculares das licenciaturas, veem-se, comumente, desobrigados a articular as teorias de referência com as demandas do ensino no local de trabalho, durante suas práticas pedagógicas (cf. GONÇALVES e FERRAZ, 2012; SOUSA et al, 2014).

Nos estudos do letramento do professor, as palavras de Kleiman (2008, p. 507) são esclarecedoras ao salientar a importância "da dimensão social e agentiva, voltada para a ação, pela linguagem, na prática social", durante a formação do professor. O conhecimento de uma teoria linguística ou literária, assimilado pelo aluno-mestre numa licenciatura, não garante o saber docente necessário para a construção de práticas escolares de linguagem nas disciplinas curriculares ou objetos de ensino em aulas de língua. A título de ilustração, retomamos as palavras da autora ao afirmar que

saber quando e em que condições se produz um texto de determinado gênero, ou como se estrutura um texto do gênero artigo de opinião, por exemplo, ou quais são alguns de seus aspectos estilísticos, não implica, de modo algum, saber como ensinar esse gênero (nem, aliás, saber escrever textos do gênero). (KLEIMAN, 2008, p. 507)

Os relatórios produzidos como trabalhos escritos finais nos estágios supervisionados são os objetos de pesquisa sobre os quais os membros do PLES vêm se debruçando mais recentemente. Esse gênero se materializa num registro acadêmico denominado de escrita reflexiva, utilizado como um instrumento para desencadear a formação profissional crítica do aluno-mestre. Neste momento, desviamos o enfo-

5 Normalmente, os estágios são iniciados no meio do curso, a partir do $5^{\circ}$ período. Talvez, essas disciplinas ou atividades semelhantes pudessem ser realizadas desde o primeiro período da licenciatura, possibilitando a imersão dos alunos-mestre no futuro contexto profissional ao ingressarem na graduação, assim como acontece nos cursos na área da saúde. 
que dos objetos de ensino e detemo-nos à interação entre as instituições de ensino envolvidas no estágio, instaurada pela escrita acadêmica reflexiva.

Dentre inúmeras demandas da formação inicial do professor, espera-se que a escrita reflexiva profissional, por proporcionar ao aluno-mestre um retorno crítico para a própria prática pedagógica, no contexto instrucional experienciado, configure-se num evento de letramento proporcionador de recontextualizações mais produtivas de saberes acadêmicos para futuras situações de ensino no local de trabalho docente. A escrita reflexiva também se configura como uma escrita autobiográfica em que há um espaço mais significativo para a manifestação da voz do aluno-mestre, quando comparado ao registro acadêmico convencional ${ }^{6}$. Nos termos de Silva (2012a, p. 41):

\begin{abstract}
A atividade de escrita dos relatórios de estágio supervisionado pode contribuir para modelar o fazer pedagógico característico dos agentes de letramento, desde que, entre outras necessidades, os alunos-mestre sejam preparados para analisar criticamente, por meio dessa atividade, as experiências do estágio supervisionado à luz das teorias acadêmicas de referência, contribuindo para o aprimoramento da própria prática profissional. Ou seja, o relatório não pode resultar num produto de uma atividade burocrática, cuja finalidade se reduz à atribuição de notas ou conceitos, quando o texto escrito produzido não encontra leitores interessados no conteúdo nele tematizado. Reduzido a instrumento de avaliação gerador de notas ou conceitos, o relatório se configura como um dos atores responsáveis pelo livre trânsito dos alunos-mestre pela licenciatura.
\end{abstract}

Do ponto de vista dos estudos do letramento, a escrita reflexiva remonta algumas contribuições originárias do que é denominado de cultura do testemunho para a aprendizagem das pessoas ${ }^{7}$. De acordo com Hamilton (2012, p. 65), "é um pequeno passo ver um testemunho pessoal como uma ferramenta empoderadora para grupos oprimidos e marginalizados - mudar experiência em evidência e verdade visível e

\footnotetext{
6 Ao focalizar algumas demandas por pesquisas a respeito da formação de professores de línguas na LA, Miller (2013, p. 113) salienta a necessidade de ouvir as vozes de alguns "marginalizados" na área de formação de professores. A autora afirma que "à semelhança do que percebo na maioria das pesquisas sobre ensino-aprendizagem, nas quais considero que alunos são pouco ouvidos, acredito que as vozes dos licenciandos ou dos professores em formação continuada estavam silenciadas antes de começarmos a pesquisar os processos de formação dentro da perspectiva da LA. Os próprios formadores de professores entraram nas pesquisas tardiamente".

7 De acordo com Hamilton (2012, p. 65), a "cultura do testemunho tem suas raízes e é utilizada nos mundos religioso e legal de testemunho e depoimento. Os usos mais antigos do depoimento são da religião Cristã - o testemunho público para a força da conversão que desenvolveu um conjunto de práticas e uma retórica de todos os seus próprios e que é amplamente familiar nas sociedades ocidentais (...). Isto foi secularizado no domínio do direito, que tomou um depoimento de uma pessoa no "jure" para ser o mais próximo da verdade e, assim, tomado com apropriada seriedade" (tradução nossa).
} 
desenvolver linguagens para descrever experiências submergidas no domínio coletivo ou público" (tradução nossa). O exercício da escrita reflexiva ou a narrativização da vida está implicado no autodesenvolvimento das pessoas.

Ainda nas palavras de Hamilton (2012, p. 65), "falar sobre nós mesmos e nossos problemas e experiências pode de alguma forma ser útil e guiar para ações positivas para mudanças pessoais e sociais" (tradução nossa). Nessa perspectiva, investigamos como a representação pela escrita reflexiva da alienação do trabalho docente, instaurada em torno de usos burocráticos do letramento, ou, em outros termos, como o testemunho da alienação nos escritos dos alunos-mestre pode contribuir para o empoderamento da formação de professores nas licenciaturas diversas, seja das próprias testemunhas diretamente, durante a própria prática de reflexão pela escrita demandada, ou, indiretamente, a partir da observação ou pesquisa científica que se debruça sobre a escrita acadêmica reflexiva dos alunos-mestre. $\mathrm{O}$ empoderamento é compreendido numa perspectiva freireana

\footnotetext{
não no sentido de dar poder a alguém, em que o sujeito "recebe" de outro algum recurso (com merecimento dele ou sem), dentro de uma perspectiva individualista, mas no sentido de ativar a potencialidade criativa de alguém, como também de desenvolver e potencializar a capacidade das pessoas. (...) não é apenas um ato psicológico, individual, mas um ato social e político, pois o ser humano, para Freire, é intrinsecamente social e político, é pessoa = relação. (...) empoderamento é o eixo que une consciência e liberdade (GUARESCHI, 2008, p. 165).
}

Ainda no tocante às investigações das interações instauradas pela escrita dos relatórios de estágio, destacamos os estudos realizados no PLES sobre representações de diferentes atores sociais vinculados ao complexo contexto dos estágios supervisionados, como professores da escola básica e os próprios alunos-mestre (PEREIRA, 2014; SILVA, 2014a; 2014b). O estudo dessas representações evidencia a relevância da escrita reflexiva profissional para o letramento do aluno-mestre, pois elas possibilitam a produção de algum diagnóstico a respeito da formação docente proporcionada pela licenciatura. Inúmeros objetos de investigação podem ser construídos na LA, considerando os relatórios focalizados como registros de pesquisa, principalmente quando são realizados relatos detalhados das vivências nos estágios supervisionados, envolvendo exemplificações de atividades didáticas ou situações de ensino, bem como [tentativas de] articulações entre saberes teóricos e práticos.

Nessa perspectiva, destacamos que, quando o enfoque de pesquisa em LA recai sobre o contexto educacional, a aula de língua não corresponde ao único escopo de análise. Conforme afirmado por Celani (1992, p. 21), "por estarem diretamente empenhados na solução de problemas bumanos que derivam dos vários usos 
da linguagem, os linguistas aplicados estão envolvidos em trabalho que tem uma dimensão essencialmente dinâmica" (itálico do original). O trabalho com a linguagem nos estágios supervisionados obrigatórios das diferentes licenciaturas se configura como um nicho promissor para a agenda investigativa da LA.

\section{LINGUÍSTICA APLICADA E FORMAÇÃO DO PROFESSOR}

Nossa visão é bastante positiva quanto à tomada do contexto complexo dos estágios supervisionados das licenciaturas como objeto de investigação da LA, ainda que, por outra perspectiva, esse cenário possa ser visto com alguma desconfiança. Vimos assumindo a noção de contexto complexo do estágio pelo fato da disciplina curricular se realizar entre duas instituições de ensino, envolvendo a participação de diferentes atores sociais, resultando numa rede dinâmica de (retro) ações (cf. MORIN, 2008). Ao tematizar a parceria entre universidade e escola nos estágios a partir da LA, Miller (2010) caracteriza as relações interpessoais a partir da referida disciplina como complexas, especialmente quando da realização da "prática exploratória", compreendida como uma estratégia sustentável de desencadeamento da interação mais estreita entre professores, alunos-mestre e demais atores sociais envolvidos nas atividades de estágio no ensino básico. Nas palavras da autora, "na escola, ao apresentar a proposta inovadora de aulas pedagógico-investigativas, o estagiário 'exploratório' complexifica ainda mais a sua situação identitária, que já é inerentemente complexa" (MILLER, 2010, p. 112).

Conforme defendido por Silva (2012a; 2011), os estágios demandam um enfoque investigativo minimamente interdisciplinar, haja vista a complexidade das interações instauradas no encontro das instituições envolvidas. Considerando o interesse pela linguagem a partir do enfoque de objetos de ensino construídos ou interações escritas instauradas, aspectos linguísticos, pedagógicos e sociais, característicos dos objetos de pesquisa, são focalizados no campo indisciplinar da LA. Esta abordagem vem resultando no diálogo entre diferentes disciplinas do conhecimento em função do empoderamento dos atores sociais envolvidos, especialmente professores da escola básica e alunos-mestre, cujas vozes, historicamente, foram desprestigiadas na universidade.

No tocante à visão negativa mencionada, há, nas licenciaturas, uma tendência de desvalorização dessas disciplinas, pois são concebidas como o momento da prática na formação inicial do professor, desprovidas do valor simbólico impregnado nas demais disciplinas, identificadas como teóricas. Situar a prática num plano se- 
cundário da formação docente configura-se como uma atitude bastante contraditória, pois essa dimensão das licenciaturas é tão importante para o empoderamento do letramento do professor quanto à teórica. Essa última dimensão também compõe os estágios supervisionados, onde a própria prática docente se configura como nicho da produção teórica, num trânsito ininterrupto, nas duas direções, entre as dimensões mencionadas.

Essa visão negativa pode ser justificada pelo fato da LA carregar um fardo muito semelhante ao dos estágios supervisionados, o que é uma herança da mentalidade acadêmica positivista. O risco estaria no enfraquecimento do campo de pesquisa e das disciplinas acadêmicas focalizadas pela ausência de prestígio que thes constitui. A esse respeito, as palavras de Celani (1992, p. 17), proferidas na década de noventa do século passado, continuam válidas:

\begin{abstract}
infelizmente, no mundo real as ciências aplicadas e, particularmente, o ensino são sempre vistos como de menor valor, em relação à ciência pura. Esse fato tem criado dificuldades que persistem até hoje, com intensidade decrescente, talvez, mas assim mesmo ainda criando obstáculos para o estabelecimento da LA como área de direito próprio.
\end{abstract}

Em meio aos conflitos ainda existentes a respeito da identidade da LA, especialmente no cenário brasileiro, é inegável as contribuições sociais originárias das pesquisas em LA para a formação de professores. De acordo com Miller (2013), as investigações científicas na área de formação docente, seja a inicial ou em serviço, desenvolvidas pelos linguistas aplicados se justificam por quatro razões que reproduzimos adiante:

Como área de investigação, ela traz, em primeira instância, fortalecimento acadêmico para as práticas de formação de professores, já que ajuda a aprofundar o entendimento dos processos de formação, tanto inicial quanto continuada. A segunda contribuição tem se manifestado no campo metodológico, a partir do momento em que as investigações na área têm desenvolvido inovações alinhadas com a pesquisa qualitativa e interpretativista nas ciências sociais. A terceira contribuição da pesquisa é de ordem política dentro da academia, já que ela tem alavancado o status institucional dos formadores de professores, tanto no Brasil quanto no exterior. A quarta contribuição da área, e talvez a mais significativa dentro da LA contemporânea, é a que se relaciona a questões de transformação social, de ética e de identidade dos diversos agentes envolvidos em processos de formação de professores (MILLER, 2013, p. 100; itálico do original).

A intensidade das dificuldades para o estabelecimento da LA parece não ter decrescido significativamente como previsto na possibilidade enunciada por Celani (1992). No cenário internacional, praticamente uma década após a publicação do 
trabalho da autora, Pennycook (2001, p. 03) afirma que LA não é meramente a aplicação de conhecimento linguístico em ambientes profissionais, como tradução, patologia da fala, letramento e educação linguística. Outro indício da existência da dificuldade de estabelecimento da LA pode ser constatado no trabalho de Hall, Smith e Wicaksono (2011, p. 15). Inicialmente, os autores utilizam o termo "linguística aplicada autônoma' para contrastar com a conceituação de linguística aplicada como disciplina irmã da linguística geral". A necessidade de distanciamento da Linguística evidencia uma LA ainda não estabelecida como "área de direito próprio".

Nos três últimos trabalhos referidos, os quais tematizam o fazer científico na LA, as práticas de linguagem nos estágios das licenciaturas são desconsideradas como objeto de investigação, diferentemente dos trabalhos brasileiros desenvolvidos por Miller $(2013$; 2010), que tematizam a formação inicial de professores de língua nos estágios obrigatórios como objeto de pesquisa na LA. Do ponto de vista da educação linguística, a ênfase dos primeiros trabalhos mencionados recai, sobretudo, no ensino de línguas adicionais, envolvendo especialmente contextos multilíngues onde relações de poder se instauram em torno de usos da língua. Porém, as concepções de LA assumidas pelos autores são aplicáveis ao contexto investigativo deste artigo. Para Hall, Smith e Wicaksono (2011, p. 17),

Linguística Aplicada é, sobretudo, uma disciplina de resolução de problemas. Enquanto qualquer projeto em Linguística Aplicada pode começar com uma descrição ou investigação empírica a respeito do papel da linguagem em um problema do mundo real, ele deve objetivar terminar com o planejamento, teste e avalição de uma solução potencial. Isto, nós acreditamos, deve ser conduzido numa colaboração próxima com as pessoas que estão experienciando o problema ou cujas necessidades precisam ser satisfeitas. (itálico do original)

Esses autores caracterizam a LA como uma disciplina que focaliza problemas envolvendo a linguagem em áreas como "comunicação, identidade social, educação, saúde, economia, política e justiça" (HALL, SMITH e WICAKSONO, 2011, p. 15). Complementando essa abordagem, menciono adiante a concepção de Linguística Aplicada Crítica - LAC -, conforme denominação assumida por Pennycook (2001). A LAC é caracterizada como uma práxis móvel, uma atitude assumida pelo linguista aplicado. $\mathrm{O}$ autor se distancia da noção de disciplina, campo ou domínio do conhecimento.

Eu vejo linguística aplicada crítica mais como uma abordagem constantemente mutável e dinâmica para questões de linguagem e educação, do que um método, um conjunto de técnicas ou um corpo fixo de conhecimento. E mais que visualizar linguística aplicada crítica como uma nova forma de conhecimento interdisciplinar, eu prefiro visualiza-la como uma forma de conhecimento antidisciplinar, como uma forma 
de pensar e fazer que é sempre passível de questionamento, sempre buscando novos esquemas de politização. (PENNYCOOK, 2001, p. 172; itálico do original)

Nesta pesquisa, assumimos uma abordagem de LA indisciplinar, configurada num campo dinâmico de investigação, informado por teorias originárias de diferentes áreas do conhecimento, as quais são mobilizadas de acordo com a complexidade visualizada no objeto de investigação. De acordo com a teoria da complexidade (MORIN, 2008), originalmente qualquer objeto de pesquisa a ser construído possui uma natureza complexa, constitui-se por uma rede dinâmica de atores em constante interação, porém, o enfoque lançado pelo pesquisador reconfigura o objeto. A complexidade desse objeto está condicionada a diversas perspectivas analíticas passíveis de realização conforme o referencial teórico mobilizado.

Complementando a abordagem aqui proposta, compartilhamos quatro critérios básicos de pesquisa, elencados por Pennycook (2001), a serem considerados na prática investigativa da LAC:

(1) um modo de funcionamento que se opõe a categorias essencialistas e esforça-se para se engajar seriamente com desigualdades; (2) a inclusão de interesses, desejos e condutas dos participantes; (3) um enfoque nas dinâmicas de poder; (4) uma orientação em direção a objetivos transformadores (PENNYCOOK, 2001, p. 161).

Este estudo da escrita reflexiva produzida a partir do encontro entre universidade e escolas de ensino básico abrange, diretamente, problemas de comunicação, identidade e educação. Mais uma vez, tomamos emprestadas as palavras de Miller (2013) a respeito da relevância da prática reflexiva do professor, assunto que também recebeu atenção na Ciência da Educação (FEIMAN-NEMSER e BEASLEY, 2007; PERRENOUD, 2002; SCHÖN, 1983; ZEICHNER, 2008) e, até mesmo, em pesquisa sobre professores em serviço na LA (LIBERALI, 2004; MAGALHÃES e CALANI, 2005):

Em sintonia com a crescente preocupação com a transformação social na educação e com a urgência de encontrar novas formas de produzir conhecimento, busca-se no século XXI, formar um professor crítico-reflexivo e ético, bem como investigar sua formação. $\mathrm{O}$ formador se insere na pesquisa, buscando atuar e entender sua própria postura crítica, reflexiva e ética. Tornam-se vitais questões como o cuidado, o respeito, a inclusão, a responsabilidade e a metarreflexão constante sobre as experiências de formação inicial e continuada (MILLER, 2013, p. 103).

Finalmente, conforme pesquisas realizadas previamente no PLES (MELO, 2012; SILVA, 2014a; 2014b; 2013; 2012c), o relatório de estágio poderia ser utiliza- 
do como um instrumento de mediação em função de uma interação mais produtiva entre as instituições de ensino envolvidas nos estágios das licenciaturas, evitando, por exemplo: (a) a escrita burocrática com apontamentos superficiais a respeito das experiências vivenciadas, restrita a uma provável leitura pelo professor supervisor; (b) a reprodução de estereótipos sobre materiais didáticos, professores, demais educadores da escola básica e suas práticas profissionais; (c) a reprodução ou a aceitação da alienação do trabalho do professor a partir das relações assimétricas estabelecidas no espaço de atuação profissional, seja pela imposição de um agir exterior ou pelo abandono de atos legais que garantiriam o trabalho docente desejado; e (d) a ratificação de constructos teóricos como elementos curriculares quase que exclusivos da licenciatura, em detrimento do impacto imponderável da transformação desse curso, caso o seu currículo também fosse, significativamente, informado por práticas sociais, conforme visto na seção anterior deste artigo.

\section{LETRAMENTO DO ALUNO-MESTRE}

Desde a década de 70, a competência linguístico-enunciativo-discursiva do professor vem sendo questionada pela mídia, universidades e secretarias de educação, conforme destacado por Kleiman (2008, p. 290). Nesse sentido, o que se questiona não é a capacidade do professor ensinar a ler, escrever ou analisar um texto, mas de produzi-lo. Ora, é possível ensinar o que ainda não se sabe fazer? Infelizmente, uma resposta afirmativa (e incoerente) para esta pergunta retórica tem sido dada no contexto educacional brasileiro. Muitos professores entram no mercado de trabalho enquanto ainda se questiona a capacidade dos mesmos em fazer aquilo para que foram habilitados a ensinar. Talvez isso ocorra porque, como já afirmou Kleiman (2008, p. 290), não é a formação do professor o alvo de crítica, mas a sua própria condição de letrado.

Refletir sobre formação de professores é indispensável para que possamos compreender a sua condição de letrados. A partir da perspectiva crítica da LA, estamos conscientes de que são múltiplos os letramentos e diversificados os saberes necessários para usar a escrita. Porém, consideramos que a questão a ser explorada, quando discutimos a formação inicial de professores, seja os saberes linguísticos relevantes para sua atuação no local de trabalho.

Tradicionalmente, os linguistas aplicados brasileiros têm investigado o letramento de professores responsáveis pela disciplina Língua Portuguesa. Essa tendência pode ser atribuída a questões culturais. Em geral, presume-se que o desenvol- 
vimento de práticas de linguagem na escola básica seja assunto do professor de língua materna, conforme evidente no Excerto 01 da Licenciatura em Geografia, reproduzido adiante. A forma adjetival diferenciada, utilizada para descrever a aula, sugere que práticas relacionadas ao uso da linguagem, como as atividades de leitura, só são legitimadas na escola quando na presença da professora de Língua Portugue$\mathrm{sa}^{8}$. Questionamos, portanto, de modo mais amplo, o letramento do professor de Geografia.

\begin{tabular}{|l|}
\hline Excerto 01. Licenciatura em Geografia \\
\hline No dia 12 de novembro em plena sexta-feira foi as 3 (tres) ultimas aulas onde era o dia \\
" $\mathrm{D}$ " da leitura e a escola colocou para nós abordar o dia da consciência Negra. Esta aula \\
foi diferenciada com a participação de todos os alunos e a professora de português onde \\
estava presente junto com nós onde abordemos o assunto, muito haver com cidadania e \\
democracia. (Seção Procedimentos Metodológicos do Relatório de Estágio V, 2010/02) \\
\hline
\end{tabular}

A prática escolar representada no Excerto 1, relatada na seção Procedimentos Metodológicos do relatório de estágio, não se configura como uma atividade interdisciplinar rotineira, onde encontramos professores responsáveis por diferentes disciplinas trabalhando cooperativamente. $\mathrm{O}$ aluno-mestre parece ser pego de surpresa pela atividade de leitura solicitada (colocou), interrompendo o planejamento das atividades didáticas em curso, situação semelhante às enfrentadas pelos próprios professores em serviço. Assim como perceptível ao longo do relatório de estágio, no excerto focalizado, o aluno-mestre não se apropria de forma significativa da reflexão pela escrita, esperada no tipo de relatório elaborado. Essa ausência demanda um maior investimento no trabalho com o gênero por parte do professor formador da licenciatura, evitando a observação ingênua por parte do aluno-mestre e, consequentemente, a reprodução da alienação do trabalho docente.

\footnotetext{
8 Todos os excertos exemplificados neste artigo foram transcritos conforme os originais em relatórios de estágio supervisionado. Não realizamos adequações linguísticas nos textos, pois acreditamos que a escrita original seja relevante quando focalizamos o letramento do aluno-mestre. Os relatórios investigados da Licenciatura em Geografia, assim como dos cursos de Letras, Química, Física e Matemática, estão disponíveis para pesquisa no Centro Interdisciplinar de Memória dos Estágios Supervisionados das Licenciaturas (CIMES), ao passo que os documentos da Licenciatura em História estão arquivados no Centro de Documentação Histórica (CDH). Esses centros estão localizados no Câmpus Universitário de Araguaína, Universidade Federal do Tocantins (UFT). Os excertos exemplificados foram inicialmente analisados na dissertação de mestrado da segunda autora deste artigo (DINIZ, 2012), quando foram investigadas práticas de leitura desenvolvidas em aulas de Geografia, História e Matemática a partir dos relatórios de estágios supervisionados obrigatórios das licenciaturas correspondentes às disciplinas escolares mencionadas.
} 
$\mathrm{Na}$ perspectiva do letramento, o ensino de língua materna objetiva proporcionar aos alunos situações em que possam vivenciar novas experiências com a linguagem enquanto prática social ou, ainda, aprofundar as que já lhes são familiares. O papel do professor de língua materna é propiciar as condições para que os alunos descubram e compreendam como o texto, objeto em torno do qual o ensino deve ser organizado, é construído. Em outras palavras, o objetivo dessa disciplina é ensinar aos alunos a articular a leitura do texto ao contexto social a que pertence, não escapando, assim, ao trabalho com gêneros. Mas, ajudar os alunos a entender o texto, apreciar e valorizar a leitura desse artefato cultural deve ser trabalho de todos os professores da escola. A mera prática social de leitura do texto de forma contextualizada atenderia minimamente às exigências curriculares nas disciplinas escolares. Deixar a responsabilidade do ensino da leitura ao professor de Língua Portuguesa equivale a "negar o valor social da leitura" (KLEIMAN e MORAES, 2003, p. 127).

Partimos, portanto, da premissa de que "cada grupo socioprofissional desenvolve suas próprias práticas sociais de uso da escrita" (KLEIMAN e MORAIS, 2003 , p. 98). A leitura enquanto atividade social compete a todos os professores porque cada professor pertence a um grupo profissional que desenvolve (conforme as identidades de cada grupo - educadores artísticos, filósofos, físicos, químicos, matemáticos e outros) diferentes "modos socialmente sancionados" de utilização da escrita (KLEIMAN e MORAES, 2003, p. 99). Segundo Bourdieu (2011), os indivíduos são condicionados socialmente, reproduzindo práticas ou gostos específicos do grupo a que pertencem. O babitus, princípio gerador destas práticas sociais, é o mecanismo pelo qual as pessoas conseguem se distinguir no espaço social. Tal distinção pode ser determinada pelo capital (econômico ou cultural/simbólico) herdado, transferido ou adquirido pelos indivíduos.

Consideramos a leitura um capital simbólico não só porque possibilita ao indivíduo acessar o acervo cultural produzido pela humanidade, mas também porque estabelece uma relação entre os mais variados campos do saber (desde que o leitor aprenda a transitar pelas especificidades de cada área). Nesse sentido, o professor de Geografia, História ou qualquer outra disciplina escolar passa a ser um modelo de leitor do grupo socioprofissional que representa. Ele "pratica a leitura da maneira como ele gostaria que o aluno lesse" (KLEIMAN e MORAES, 2003, p. 99), ou seja, estabelecendo as conexões que são relevantes para desenvolver a competência no uso da linguagem ou expressar uma interpretação que contribua para a compreensão da Geografia, História e demais disciplinas. Em outras palavras,

aprender a ler como um historiador lê e a valorizar os documentos e fontes primárias que o historiador valoriza é competência do professor de História: as macrorrelações que o professor estabelece entre períodos históricos, a análise causal de fenômenos 
contemporâneos que ele constrói com base em grandes cadeias inferenciais são modos de ler que o professor de história já aprendeu; daí ele poder modelá-los e mediar, através de perguntas e comentários, os textos de sua área. Já a exatidão e a precisão de uma conclusão na leitura do matemático, por outro lado, que não permite inferências pragmáticas da lógica natural da linguagem, são melhor modeladas pelo professor cuja socialização profissional se deu através de leituras desse tipo. A especificidade de alguns tipos de textos - como os mapas, as tabelas estatísticas, os documentos e fontes primárias - necessita da leitura do especialista que aprendeu, através da prática social - as formas legitimadas pela instituição de tratar esses textos (KLEIMAN e MORAES, 2003, p. 100).

$\mathrm{Na}$ perspectiva dos estudos do letramento, questionamos a formação dos alunos-mestre em diferentes licenciaturas. Investigamos relatórios de estágio supervisionado porque os consideramos instrumentos que podem, por meio da escrita reflexiva, contribuir significativamente para o letramento do professor em formação inicial. Concordamos com Green (2001, p.10), quando afirma que "o modo mais efetivo de desenvolver leitores críticos é através da escrita". Consideramos a escrita reflexiva acadêmica, contextualizada e orientada por leituras diversas, um instrumento empoderador na formação do aluno-mestre, pois permite subverter e resistir à ordem dominante ou à alienação imposta.

Questionar a formação inicial do aluno-mestre, assim como as demandas do futuro local de trabalho antes de questionar o letramento do professor é, em nossa visão, imprescindível, num contexto educacional que há muito já se rendeu ao sistema capitalista de produção. Afirmamos isso porque, de modo geral, o trabalho do professor é alienante. Ele não se reconhece no produto do seu trabalho e "serve a funções que pouco tem a ver com seus próprios objetivos e intenções" (KLEIMAN e MORAES, 2003, p. 36). Sobrecarregado pela burocracia, pelo número excessivo de aulas, quase sempre, não lhe sobra tempo para planejar, discutir projetos com os colegas de trabalho ou mesmo estudar. Além disso, o desprestígio da profissão e a má-remuneração fazem com que o professor "produza algo cujo sentido lhe escapa" (KLEIMAN e MORAES, 2003, p. 36).

A alienação imposta ao professor pode ser exemplificada a partir da pesquisa realizada por Bronckart e Machado (2004), ao proporem alguns procedimentos de análise de textos sobre o trabalho educacional. Os autores analisaram a carta de apresentação dos Parâmetros Curriculares Nacionais - PCN, assinada pelo então Ministro da Educação e do Desporto, e direcionada ao professor do ensino básico. Segundo os autores, na carta são atribuídas capacidades positivas apenas aos professores que participaram da produção dos documentos. Aos professores do ensino básico, destinatários da mensagem, "não são atribuídas nem intenções, nem capacidades próprias, sendo mostrados apenas como participantes futuros de uma 
série de atividades previstas pelo agir prescrito" no documento (BRONCKART e MACHADO, 2004, p. 156).

A análise de relatórios de estágio supervisionado nos revelou que questões relacionadas ao processo de alienação do profissional docente estão presentes de tal modo no ambiente escolar que são percebidas muito cedo pelos alunos-mestre, já nos primeiros períodos de estágio, momento em que são feitas observações na escola. A alienação ocorre pela submissão do professor a documentos legais ou, até mesmo, pelo descredito incorrido por escritos desse tipo no espaço de atuação profissional, conforme revela o Excerto 02 da Licenciatura em Geografia.

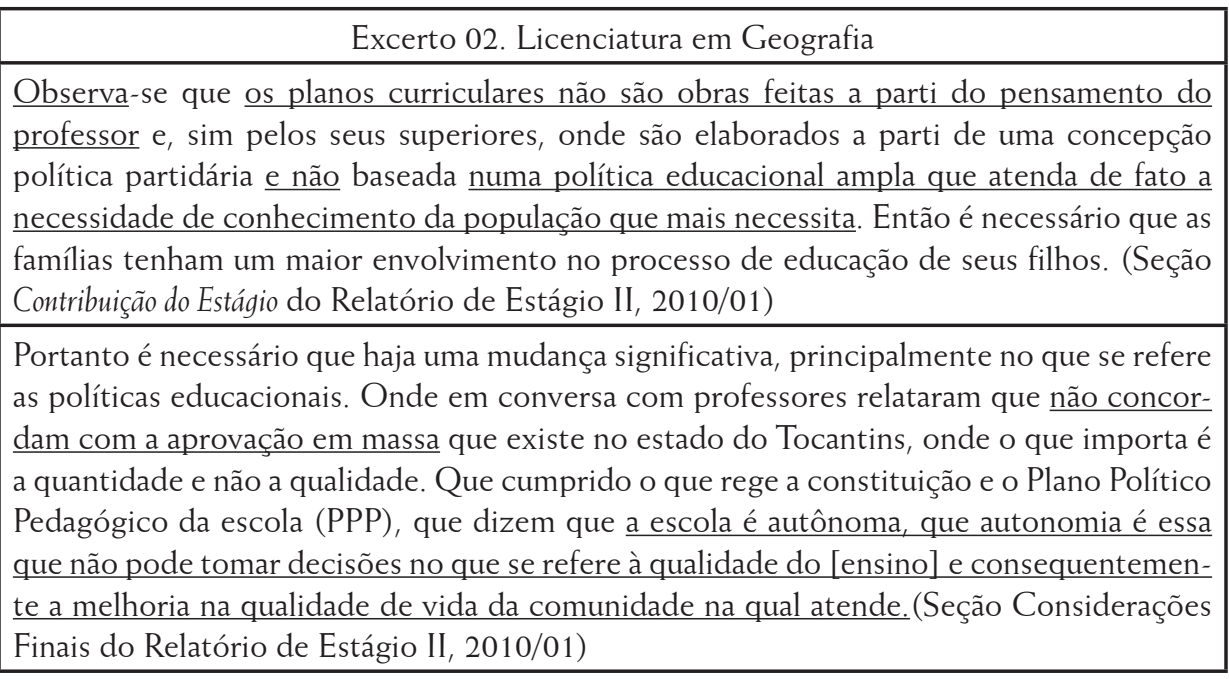

O Excerto 02 mostra que o processo de alienação percorre forçosamente todas as etapas do trabalho docente, desde a elaboração do currículo escolar (os planos curriculares não são obras feitas a parti do pensamento do professor) até a avaliação discente (não concordam com a aprovação em massa), sendo todas as atividades marcadas pela linearidade e usurpação da autonomia da escola e do professor. Bronckart e Machado (2004) consideram que a própria elaboração de uma base curricular para todas as escolas do país, iniciada em meados de 1994, a partir de pesquisas no campo das Ciências da Educação e que, posteriormente, resultaram documentos norteadores do ensino (parâmetros curriculares nacionais e orientações complementares), configuram "o gesto fundador do controle pelo Estado da qualidade de ensino desejada" (BRONCKART e MACHADO, 2004, p. 143).

O Excerto 02 mostra que a escrita reflexiva é produzida a partir da percepção do contexto do estágio obrigatório pelo aluno-mestre (observa). Além de descrever a 
situação de vulnerabilidade descrita no trabalho docente, o aluno-mestre contrapõe (e não) tal situação à politica educacional desejada conforme saberes aprendidos na universidade (baseada numa política educacional ampla que atenda de fato a necessidade de conbecimento da população que mais necessita). O aluno-mestre ainda demanda o envolvimento da família como uma resposta ao tipo de embate a ser assumido junto aos professores diante das práticas cerceadoras da política educacional local (é necessário que as famílias tenham um maior envolvimento no processo de educação de seus filhos).

Nas considerações finais do relatório, o aluno-mestre ratifica a necessidade de mudanças na política educacional. A voz dos professores também é trazida para a elaboração da escrita do relatório (em conversa com professores relataram), caracterizando o estágio como o momento da troca de saberes entre alunos-mestre e professores colaboradores, e a escrita reflexiva como um valioso instrumento de mediação na construção da conscientização crítica do professor em formação inicial.

Outro exemplo de alienação do trabalho do professor em função das políticas educacionais locais foi encontrado num questionário elaborado por alunas-mestre do primeiro estágio supervisionado por elas cursado na Licenciatura em História. O questionário foi respondido pela professora da escola-campo observada, servindo apenas como um tipo de atividade de geração de informações, uma vez que os questionários não foram alvo de análises críticas. No Excerto 03, reproduzimos uma questão que revela a prática de escolha do livro didático, a qual reproduz a falta de credibilidade no trabalho docente, além das relações assimétricas existentes no sistema escolar.

\section{Excerto 03. Licenciatura em História}

Pergunta 18 do Questionário: Quais os requisitos usados para a escolha do livro didático? Resposta: Da última vez (3 anos atrás) tivemos uma única tarde para fazer essa escolha. (Anexo do Relatório I, 2010/01)

Além de escamotear a pergunta, a professora revela na resposta o contexto ao qual foi submetida por ocasião da escolha do livro. O escamoteamento, provavelmente, justifica-se pelo fato de a professora colaboradora não conseguir definir exatamente quais critérios utilizara ou considerara relevantes para a escolha do livro didático. As expressões que utiliza (da última vez; uma única tarde) geram um efeito de sentido de insatisfação, sentimento que a professora desejava expressar em relação ao processo de escolha do livro didático. Ela enfatiza que foi há três anos e que o tempo empregado para a escolha certamente não tenha sido suficiente para uma análise criteriosa. 
No Excerto 04, a Pergunta 19 demonstra mais claramente que a autonomia, princípio tão ditado nos documentos oficiais que devem orientar o ensino básico, não é garantido no trabalho docente.

\section{Excerto 04. Licenciatura em História}

Pergunta 19 do Questionário: Você participa dessa escolha?

Resposta: Sim, mas nem sempre o livro escolbido é o que é enviado às escolas. (Anexo do Relatório I, 2010/01)

A resposta apresentada para a pergunta do Excerto 04 é um forte indício de que o livro adotado pela escola não foi o mesmo da escolha realizada pela professora. Esse fato pode ter gerado o descontentamento da docente, e, por conseguinte, uma ausência de compromisso com a proposta didática do livro. Conforme demonstrou a pesquisa realizada por Diniz (2012), o registro no relatório de estágio revelou que a professora rejeita algumas atividades e textos propostos no livro didático, substituindo-os por questionários que pouco contribuem para o letramento crítico do aluno. Embora a professora consiga subverter a ordem quando se nega a trabalhar as atividades já previamente determinadas pelo livro didático, continua num processo de alienação e ausência de voz porque as atividades que propõe ao fazer o que chama de "transposição didática", espelham os métodos tradicionais de trabalho com a leitura na escola.

Finalmente, sob o ponto de vista da Análise do Discurso, Santos (2010, p. 152), ao interpretar algumas projeções sobre o professor tocantinense em documentos oficiais, considera que o referido professor, "ora é instigado a ser agente, ora é instigado a se assujeitar às orientações determinadas por superiores sem questionar". Segundo a autora, algumas vezes, o professor é projetado no discurso "como um profissional ainda muito aquém do mínimo desejado; em outras, como alguém obrigado a fazer malabarismos para dar conta das exigências sobre ele lançadas, independente das condições de produção e de realização de seu trabalho".

\section{CONSIDERAÇÕES FINAIS}

O estudo realizado nos mostrou que as pesquisas realizadas por linguistas aplicados podem contribuir significativamente para o trabalho com a linguagem na formação dos alunos-mestre em licenciaturas diversas, não estando o escopo da LA restrito aos cursos superiores de formação inicial de professores de línguas. Para 
tanto, o percurso indisciplinar, caracterizado pela "abordagem constantemente mutável e dinâmica" (PENNYCOOK, 2001, p. 172), envolvendo diferentes áreas do conhecimento, faz-se necessário diante dos vastos recortes investigativos a nossa espera. Por outro lado, trazer o contexto dos estágios obrigatórios de diferentes licenciaturas para a agenda dos linguistas aplicados também contribui para fortalecimento da LA no campo das políticas públicas de pesquisa educacional nacional.

No tocante às formas de alienação do trabalho docente, testemunhadas nos relatórios de estágio e envolvidas em usos da tecnologia da escrita, somos levados a acreditar que o professor, muitas vezes, não é visto como um profissional autônomo, capaz de pensar e fazer escolhas. O direito de escolha é concedido desde que cerceado de alguma maneira. Nas licenciaturas, validar essa hipótese seria o mesmo que reconhecer o fracasso das universidades em formar os professores enquanto agentes de letramento. O papel dos estágios obrigatórios das diferentes licenciaturas e, inclusive, do exercício da escrita acadêmica reflexiva na formação inicial, é essencial para a desestabilização de práticas institucionais danosas que atravessam o trabalho docente.

Finalmente, salientamos que confluências de fatores culturais e socioeconômicos, configuradores do mundo do trabalho docente, constituem, muitas vezes, um círculo vicioso que prende os professores em posições sociais subalternas (cf. KLEIMAN e MARTINS, 2007). Ser considerado letrado e mais, assumir o papel de agente de letramento é uma ação de tamanha envergadura que o professor, independente da área em que atue, precisa ter familiaridade com as práticas de letramento de diversas instituições ou domínios sociais, particularmente aqueles legitimadas pelos grupos dominantes. Mesmo sabendo ler e escrever e estando diariamente exposto a eventos de letramento, o fato de estar alheio a práticas sociais diferentes daquelas específicas ao ambiente acadêmico e escolar, conduziria a um efeito de desempoderamento, efeito contrário ao que se espera das práticas de letramento - o de instrumentar o ator social para a intervenção crítica na sociedade.

\section{REFERÊNCIAS BIBLIOGRÁFICAS}

BOURDIEU, P. (2011). Razões práticas: sobre a teoria da ação. 11 $1^{\text {a }}$. Ed. São Paulo: Papirus.

BRITO, C. C. de P. (2014). Olhares sobre as práticas de linguagem na aula de língua inglesa em contexto de estágio supervisionado. Raído. Dourados: EdUFGD, v. 8. n. 15 , pp. 117-134. 
BRONCKART, J-P.; MACHADO, A. R. (2004). Procedimentos de análise de texto sobre o trabalho educacional. In: MACHADO, A. R. O ensino como trabalbo. Londrina: EDUEL, pp. 131-166.

CELANI, M. A. (1992). Afinal, o que é Linguística Aplicada? In: PASCHOAL, M.; CELANI, M. (orgs.). Linguística Aplicada: da Aplicação da Linguística à Linguística Transdisciplinar. São Paulo: Educ. pp. 15-23.

DINIZ, A. L. S. (2012). Práticas de leitura propostas por professores na formação inicial em diferentes licenciaturas: investigando relatórios de estágio supervisionado. Dissertação de Mestrado em Letras: Ensino de Língua e Literatura - Campus Universitário de Araguaína, UFT, Araguaína.

FEIMAN-NEMSER, S.; BEASLEY, K. (2007). Discovering and sharing knowledge: inventing a new role for cooperating teachers. In: D. Carroll et al. (ed.). Transforming teacher education: reflections from the field. Cambridge, MA: Harvard Education Press, pp. $139-160$.

GONÇALVES, A. V.; FERRAZ, M. R. R. (2012). Teoria acadêmica e prática profissional na Licenciatura em Letras. In: In: SILVA, W. R. (org.). Letramento do professor em formação inicial: interdisciplinaridade no estágio supervisionado da licenciatura. Campinas: Pontes Editores, pp. 109-136.

GONÇALVES, A. V.; FERRAZ, M. R. R.; SILVA, W. R. (2014). Apresentação: estágio supervisionado nas licenciaturas. Raído. Dourados: EdUFGD, v. 8. n. 15, pp. 7-10.

GREEN, P. (2001). Critical literacy revisited. In: FEHRING, H.; GREEN, P. (orgs.). Critical literacy: a collection of articles from the Australian Literacy Educators' Association. Delaware: International Reading Association, pp. 7-14.

GUARESCHI, P. (2008). Empoderamento. In: STRECK, D. R.; REDIN, E.; ZITKOSKI, J. J. (orgs.). Dicionário Paulo Freire. Belo Horizonte: Autêntica Editora, pp. 165-166.

GUERRA, M. M. (2012). Percursos de professores de línguas nos primeiros momentos do fazer no magistério - entre práticas de letramento, saberes e alguns entremeios. Dissertação de Mestrado em Letras: Ensino de Língua e Literatura - Campus Universitário de Araguaína, UFT, Araguaína. HALL, C. J.; SMITH, P. H.; WICAKSONO, R. (2011). Mapping Applied Linguistics: a Guide for Students and Practitioners. London: Routledge.

HAMILTON, M. (2012). Literacy and the politics of representation. London: Routledge.

KANEOYA, M. L. C. (2014). A formação pré-serviço do professor de língua em curso de licenciatura: crenças e reflexões em experiências de estágios supervisionados em diferentes contextos (sala de aula teletandem). Raído. Dourados: EdUFGD, v. 8. n. 15 , pp. 249-264.

KIELING, J. F. (2008). Alienação. In: STRECK, D. R.; REDIN, E.; ZITKOSKI, J. J. (orgs.). Dicionário Paulo Freire. Belo Horizonte: Autêntica Editora, pp. 36-37.

KLEIMAN, A. B. (2008). Os estudos de letramento e a formação do professor de língua materna. Linguagem em Discurso. Tubarão: UNISUL, v. 8, n. 3, pp. 487-517. 
KLEIMAN, A. B. (2006). Processos identitários na formação profissional: o professor como agente de letramento. In: CORRÊA, M. L. G.; BOCH, F. (orgs.). Ensino de Lingua: representação e letramento, pp. 75-91.

KLEIMAN, A. B. ; MARTINS, M. S. C. (2007). Formação de professores: a contribuição das instâncias administrativas na conservação e na transformação de práticas docentes. In: KLEIMAN, A. B. e CAVALCANTI, M. C. (orgs.). Linguística Aplicada: suas faces e interfaces. Campinas: Mercado de Letras. pp. 273-298.

KLEIMAN, A. B. ; MORAES, S. E. (2003). Leitura e interdisciplinaridade: tecendo redes nos projetos da escola. $3^{\text {a }}$. ed., Campinas: Mercado das Letras.

LIBERALI, F. (2004). Getting ready to conduct a reflective session. The Especialist. São Paulo: PUC, v. 25. n. especial, pp. 23-38.

MAGALHÃES, M.; CALANI, M. (2005). Reflective sessions: a tool for teacher empowerment. Revista Brasileira de Linguística Aplicada. Belo Horizonte: UFMG/ALAB, v. 5. n. 1, pp. 135-160.

MELO, L. C. (2012). Escrita acadêmica na profissionalização do professor de língua estrangeira. In: SILVA, W. R. (Org.). Letramento do professor em formação inicial: interdisciplinaridade no estágio supervisionado da licenciatura. Campinas: Pontes Editores, pp. 181-206.

MELO, L. C.; ANDRADE, K. dos S.; SILVA, W. R. (2012). Trabalho escolar com vocabulário em relatórios de estágios supervisionados em ensino de língua inglesa. Trabalhos em Linguística Aplicada. Campinas: IEL/UNICAMP, v. 51, pp. 51-75.

MELO, L. C.; GONÇALVES, A. (2014). Projeções como práticas acadêmicas de citação na escrita reflexiva profissional de relatórios de estágio supervisionado. Raído. Dourados: EdUFGD, v. 8. n. 15, pp. 45-70.

MILLER, I. K. (2010). Construindo parcerias universidade-escola: caminhos éticos e questões crítico-reflexivas. Telma Gimenez; Maria Cristina de Góes Monteiro (orgs.). Formação de Professores de línguas na América Latina e transformação social. Campinas: Pontes, pp. 109-129.

MILLER, I. K.. (2013). Formação de professores de línguas: da eficiência à reflexão crítica e ética. In: LOPES, L. P. da M. (org.). Linguística Aplicada na modernidade recente: festschrift para Antonieta Celani. São Paulo: Parábola, pp. 99-121.

MORIN, E. (2008). Introdução ao pensamento complexo. $5^{\text {a }}$ ed. Lisboa: Instituto Piaget.

OLIVEIRA, C. P.; FERREIRA, R. V. (2014). Estágio supervisionado e docência indígena: um caso Karajá. Raído. Dourados: EdUFGD, v. 8. n. 15, pp. 283-295.

PENNYCOOK, A. (2001). Critical Applied Linguistics: a critical introduction. New York/ London: Routledge.

PEREIRA, B. G. (2014). Professores em formação inicial no gênero relatório de estágio supervisionado: um estudo em licenciaturas paraenses. Dissertação de Mestrado em Letras: Ensino de Língua e Literatura. Campus Universitário de Araguaína - UFT, Araguaína. 
PERRENOUD, P. (2002). A prática reflexiva no oficio de professor: profissionalização e razão pedagógica. Porto Alegre: Artmed.

SANTOS, J. S. dos. (2010). Discurso sobre e de professores de lingua materna no estado do Tocantins: modos de posicionamento do e em relação ao discurso oficial. 2010.183f. Tese (Doutorado em Linguística Aplicada). Instituto de Estudos da Linguagem Universidade Estadual de Campinas.

SCHÖN, D. (1993). The reflective practitioner: how professional think in action. London: ASHGATE.

SILVA, W. R. (2014a). Reflexão pela escrita no estágio supervisionado da licenciatura: pesquisa em Linguística Aplicada. Campinas: Pontes Editores.

SILVA, W. R.. (2014b) Linguística Sistêmico-Funcional como uma teoria para análise de dados em Linguística Aplicada: escrita reflexiva do aluno-mestre. DELTA: Documentação de Estudos em Linguística Teórica e Aplicada. São Paulo: PUC/SP. (a sair)

SILVA, W. R.. (2013). Escrita do gênero relatório de estágio supervisionado na formação inicial do professor brasileiro. Revista Brasileira de Linguística Aplicada. Belo Horizonte: UFMG/ALAB, v. 13, n. 1, pp. 171-195.

SILVA, W. R.. (2012a). Estudos do letramento do professor e formação inicial nos estágios supervisionados das licenciaturas. In: SILVA, W. R. (org.). Letramento do professor em formação inicial: interdisciplinaridade no estágio supervisionado da licenciatura. Campinas: Pontes Editores, pp. 27-49.

SILVA, W. R.. (2012b). Práticas escolares de leitura em estágio supervisionado: por uma formação crítica do professor. In: GONÇALVES, A. V.; PETRONI, M. R. (orgs.). Formação inicial e continuada de professores: o múltiplo e o complexo nas práticas educativas. Dourados: EDUFGD, pp. 135-166.

SILVA, W. R.. (2012c). Proposta de análise textual-discursiva do gênero relatório de estágio supervisionado. DELTA: Documentação de Estudos em Linguística Teórica e Aplicada. São Paulo: PUC/SP, v. 28, n. 2, pp. 281-305.

SILVA, W. R.. (2011). Prefácio: por um campo de investigação interdisciplinar próprio para os estágios supervisionados das licenciaturas. In: Adair V. Gonçalves; Alexandra S. Pinheiro; Maria F. Ferro (orgs.). Estágio e práticas educativas: diálogos interdisciplinares. Dourados: Editora da UEMS, pp. 5-8.

SILVA, W. R.. (2008). Construção e mistura de saberes em projetos de ensino produzidos por professores em formação inicial. In: Norma Lúcia da Silva. (Org.). Construindo saberes: o ensino por projetos nas licenciaturas - experiências docentes. Goiânia: Grafset - Gráfica e Editora Ltda, pp. 53-80.

SILVA, W. R.; MELO, L. C. (2010). Práticas escolares de linguagem propostas em estágio supervisionado de língua inglesa. Revista do GELNE, v. 12, pp. 72-82.

SILVA, W. R.; PEREIRA, B. G. (2013). Letramento acadêmico no estágio supervisionado da licenciatura. Raído. Dourados: EdUFGD, v. 7, n. 13, pp. 37-60. 
SILVA, W. R.; RÊGO, N. S. (2013). Apropriação de saberes sobre prática de escrita por professores de língua materna em formação inicial. In: Adair Vieira Gonçalves; Milene Bazarim. (orgs.). Interação, gêneros e letramento: a (re)escrita em foco. 2ed. Campinas: Pontes Editores, pp. 197-220.

SILVA, W. R.; SANTOS, J. S.; FARAH, B. F. (2014). Sustentabilidade eletramento do professor em formação inicial: demandas inovadoras para atividades acadêmicas de ensino e de pesquisa. Araguaína: UFT, (no prelo).

SOUSA, C. T.; LUCENA, J. M.; SEGABINAZ, D. (2014). Estágio supervisionado e ensino de língua portuguesa: reflexões no curso de Letras/Português da UFPB. Raído. Dourados: EdUFGD, v. 8. n. 15, pp. 205-226.

TAVARES, E. (2011). Práticas de escrita escolar propostas na formação inicial de professores de diferentes licenciaturas: investigando relatórios de estágio e diretrizes curriculares oficiais. Dissertação de Mestrado de Letras: Ensino de Língua e Literatura - Campus Universitário de Araguaína, UFT, Araguaína.

TAVARES, E.; SILVA, W. (2014). Escritas propostas para diferentes disciplinas escolares e formação do professor nas licenciaturas. In: SILVA, L. H. O. da; MELO, M. A. de; OLIVEIRA, L. R. P. F. de. (orgs.). Ensino de Lingua e Literatura: pesquisas na Pós-graduação, Palmas: EdUFT, pp. 97-120.

TAVARES, E.; SILVA, W. (2012). Práticas de escrita escolar nos estágios supervisionados das licenciaturas em Geografia, História e Matemática. In: SILVA, W. R. (org.). Letramento do professor em formação inicial: interdisciplinaridade no estágio supervisionado da licenciatura. Campinas: Pontes Editores, pp. 231-255.

VALSECHI, M. C.; KLEIMAN, A. B. (2014). O estágio supervisionado e a voz social do estagiário. Raído. Dourados: EdUFGD, v. 8. n. 15, pp. 13-32.

ZEICHNER, K. (2008). Uma análise crítica sobre a "reflexão" como conceito estruturante na formação docente. Educação e Sociedade: Revista de Ciência da Educação. Campinas: Unicamp, v. 29, n. 103, pp. 535-554,

Recebido: 23/05/2014

Aceito: 28/11/2014 
